\title{
PENERAPAN PENGGUNAAN BUILDING AUTOMATION SYSTEM UNTUK PENGOPERASIAN CHILLER DI BANDARA SYAMSUDIN NOOR
}

\author{
Teguh Prianto ${ }^{1}$ \\ Prodi teknik elektro,Universitas Islam Kalimantan MAB ${ }^{1}$ \\ teguh.prianto77@gmail.com ${ }^{1}$
}

\begin{abstract}
Abstrak - Semakin tinggi tingkat industri dan perusahaan semakin besar pula tingkat kebutuhan tenaga listrik untuk memenuhi kebutuhan energinya. Terutama energi listrik pada mesin pendingin seperti Chiller,sehingga upaya penghematan energi listrik yang dapat berpengaruh ke biaya listrik yang digunakan. Pada dasarnya pengoperasian Chiller di Bandara Syamsudin Noor masih dilakukan dengan cara manual yang harus ada operator ke lokasi untuk menyalakan dan mematikan sesuai jam yang ditentukan, dengan banyaknya peralatan yang di harus dioperasikan dan keterbatasan SDM. untuk mengatasi masalah di lapangan sehingga menerapkan Building
\end{abstract} Automation System untuk pengoperasian Chiller. bertujuan Mengetahui pengaruh penggunaan Bulding Automation System terhadap konsumsi energi listrik dan biaya operasional yang digunakan pengoprasian Chiller yang mempunyai beberapa cara pengoperasian yaitu secara manual,Schedule link dan Sequencing. Metode yang digunakan adalah dimulai dari pengumpulan data peralatan, pengukuran peralatan yang dapat diaplikasikan dengan BAS, membuat Wiring Diagram pada BAS, melakukan simulasi pengoperasian dengan program Schedule link. Salah satu upaya dapat menghemat energi listrik dan biaya operasional, penerapan Building Automation System untuk mengoperasikan Chiller dan monitoring terdapat penurunan pengunaan energi listrik sebesar 2,484 Kwh jika di konversikan ke rupiah terdapat penurunan biaya sebesar Rp 2.713.632 Melihat penurunan Konsumsi energi listrik dan biaya listrik yang digunakan untuk pengoperasian Chiller menggunakan Building Atomation System sangat menguntungkan bagi perusahaan dan lebih efesien dalam pekerjaan pengoperasian Chiller.
Kata Kunci : Chiller, Building Automation System, Direct Digital Control

\section{PENDAHULUAN}

Penerapan penggunaan Building Automation System untuk pengoperasian dan monitoring Chiller. Dengan menggunakan Building Automation System (BAS) akan memudahkan operator dalam melakukan kontrol terhadap kinerja Chiller yang harus dimonitoring setiap saat, dan apabila terjadi gangguan maka operator akan langsung mengetahui apa jenis permasalahan yang terjadi pada Chiller tersebut. (Wahyono,\& Teguh.2017). Adapun fungsi Chiller adalah sebagai peralatan utama mesin pendingin di Bandara Syamsudin Noor. dengan jumlah chiller 6 unit masing-masing mempunyai kapasitas 409 TR (Tons of Refrigeration) untuk mendinginkan gedung terminal seluas $7700 \mathrm{~m} 2$. dengan cara mengolah air yang diproses oleh Chiller, setelah air sudah menjadi dingin akan dipompa melalui instalasi pipa yang terhubung dengan pompa yang akan dialirkan ke AHU (Air Handling Unit) dan FCU (Fan Coil Unit) sehingga air diolah menjadi udara dingin, untuk mendinginkan ruangan terminal bandara yang dialirkan melalui instalasi ducting yang sudah terhubung dengan diffuser.

Permasalahan yang sekarang terdapat di lapangan banyaknya peralatan yang harus dioperasikan pada saat terminal bandara mulai beroperasi. dengan keterbatasannya petugas atau operator untuk mengoperasikan peralatan mekanikal dan elektrikal. Dengan terciptanya permasalahan di lapangan, untuk mengatasi masalah sehingga menerapkan penggunaan Building Automation System pada Chiller dengan bertujuan untuk mempermudah operator dalam pengoperasian dan monitor chiller pada saat gedung terminal beroperasi dengan bertujuan 
apabila terjadi gangguan operator langsung mengetahui apa jenis permasalahan yang terjadi pada chiller. serta bertujuan untuk meminimalisir biaya listrik dan tidak perlu banyaknya operator untuk mengoperasikan dan monitoring chiller. Dengan terpasangnya BAS, operator tidak perlu lagi datang ke lokasi untuk mengoperasikan dan monitor chiller. Karna pada BAS terdapat beberapa cara untuk menghidupkan Chiller, dengan cara pengoperasian lewat komputer, Schedule link dan Sequencing. sehingga kedepannya tidak perlu adanya penambahan operator untuk pengoperasian chiller.

\section{Metode Penelitian}

Jenis penelitian yang digunakan dalam penelitian ini adalah Observasi Lapangan Penerapan Penggunaan Building Automation System untuk pengoperasian Chiller dilakukan di Bandara Syamsudin Noor. Waktu penelitian dimulai dari bulan Oktober sampai selesai. Dimana dalam Penelitian ini akan dilakukan pengambilan data-data peralatan dan jam operasional Chiller. Data-data yang didapat selanjutnya akan diolah untuk didapatkan indeks yang diinginkan yaitu yang sesudah dan sebelum dilakukannya penelitian. Data yang diolah nantinya akan dideskripsikan pada proses penerapan sistem kontrol Chiller.

\section{Hasil dan Pembahasan}

\section{A. Data Operasional Chiller Dengan Cara Manual}

Pengoperasian Chiller Sebelum adanya perencanaan penggunaan Building Automation System masih dilakukan secara manual, dengan cara menghidupkan langsung dari panel Chiller sehingga dengan jumlah Chiller sebanyak 6 unit yang hidup dan matinya harus bergantian sesuai jam operasional yang ditentukan dengan cara menyesuaikan kebutuhan kapasitas pendingin di terminal serta memperhatikan suhu udara luar dan jumlah penumpang. Pada tabel jam operasional terdapat jumlah, jam operasional, kebutuhan energi listrik dan biaya listrik dalam 1 hari yang digunakan untuk menghidupkan Chiller. dengan perhitungan sebelum menggunakan BAS daya listrik yang digunakan adalah:

1. Total Beban LWBP x Tarif LWBP 28,152 Kwh x p1090,78 = Rp 30,707,639

2. Total Beban WBP x Tarif WBP 2,484 Kwh x Rp 1608, $67=\operatorname{Rp} 3,995,396$

Total tarif $\mathrm{LWBP}+\mathrm{WBP}=\mathrm{Rp} 34,703,535$

Dengan adanya perhitungan beban dan biaya listrik, sehingga dibuatlah tabel penggunaan daya listrik selama operasional yang dikonversikan kebiaya operasional. adapun tabel jam operasional yang diterapkan selama ini untuk mengoperasikan Chiller secara manual adalah sebagai berikut:

Tabel 1. Data operasional Chiller dengan cara manual dalam satu minggu

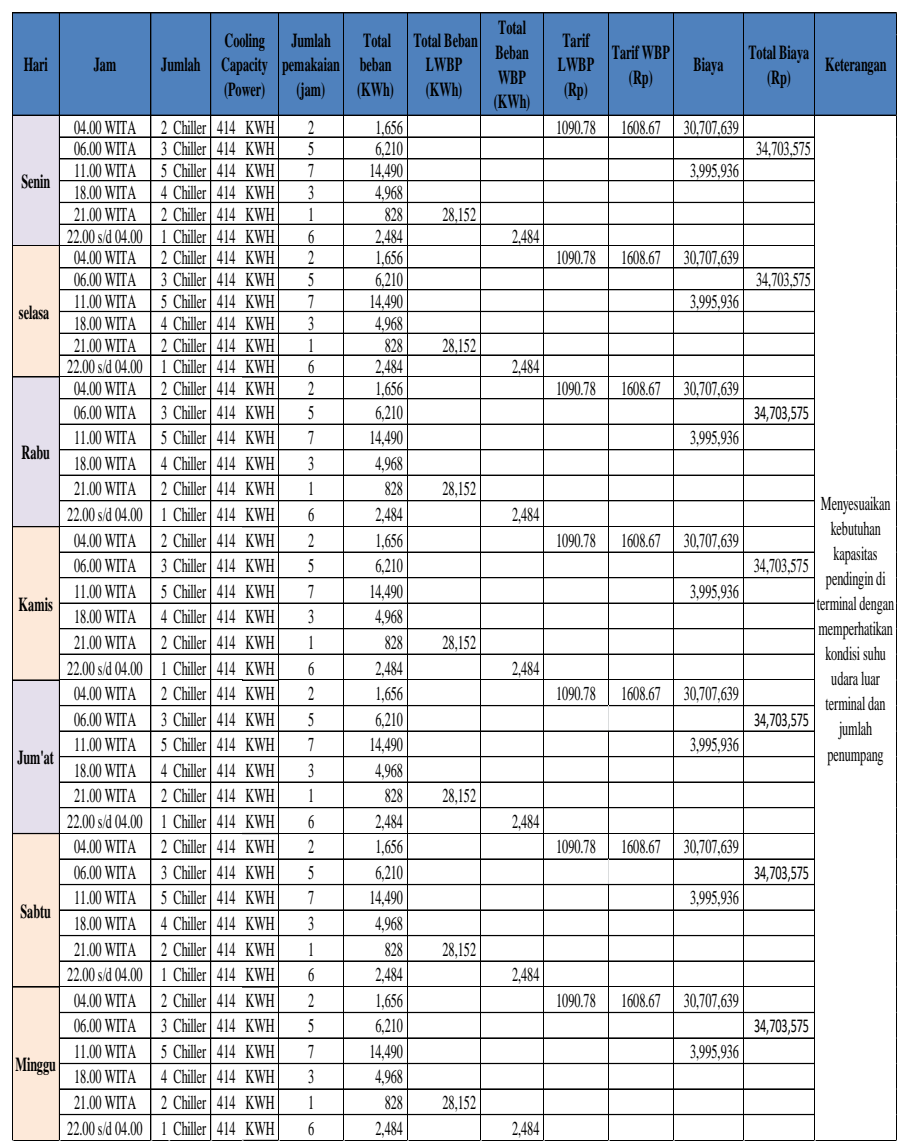

\section{B. Data}

Menggunakan
Chiller

BAS 
Pada pelaksanaan Penerapan Building Automation System untuk pengoperasian Chiller terdapat beberapa cara untuk pengoperasian Chiller yaitu dengan cara manual, Schedule link, Squencing, dan dapat dimonitor dari jarak jauh dengan adanya beberapa cara untuk pengoperasian Chiller maka terdapat tabel pengopersian Chiller dengan cara Schedule link yang mana tabel tersebut menjelaskan pengaturan jam operasional secara otomatis untuk hidup dan matinya Chiller. sehingga kita tidak perlu lagi menghidupkan secara manual dari komputer yang sudah terhubung dengan Building Automation System. Dengan menggunakan program Schedule link yang terdapat pada bagian Building Automation System, berpengaruh terhadap konsumsi energi listrik dan biaya operasional Chiller, adapun perhitungan konsumsi energi listrik yang dikonversikan biaya tarif listrik adalah sebagai berikut:

\section{Total Beban LWBP x Tarif LWBP} 25,668 Kwh x Rp 1090,78 = Rp 27,998,141

2. Total Beban WBP $x$ Tarif WBP 2,484 Kwh x Rp 1608,67 = Rp 3,995,396 Total tarif LWBP + WBP $=\operatorname{Rp} 31,994,007$

Dengan adanya perhitungan beban dan biaya listrik, sehingga dibuatlah tabel penggunaan daya listrik selama operasional yang dikonversikan kebiaya operasional. adapun tabel jam operasional dengan program Schedule link yang diterapkan untuk mengoperasikan Chiller secara otomatis menggunakan Building Automation System sebagai berikut:
Tabel 2. Data penerapan operasional Chiller menggunakan BAS

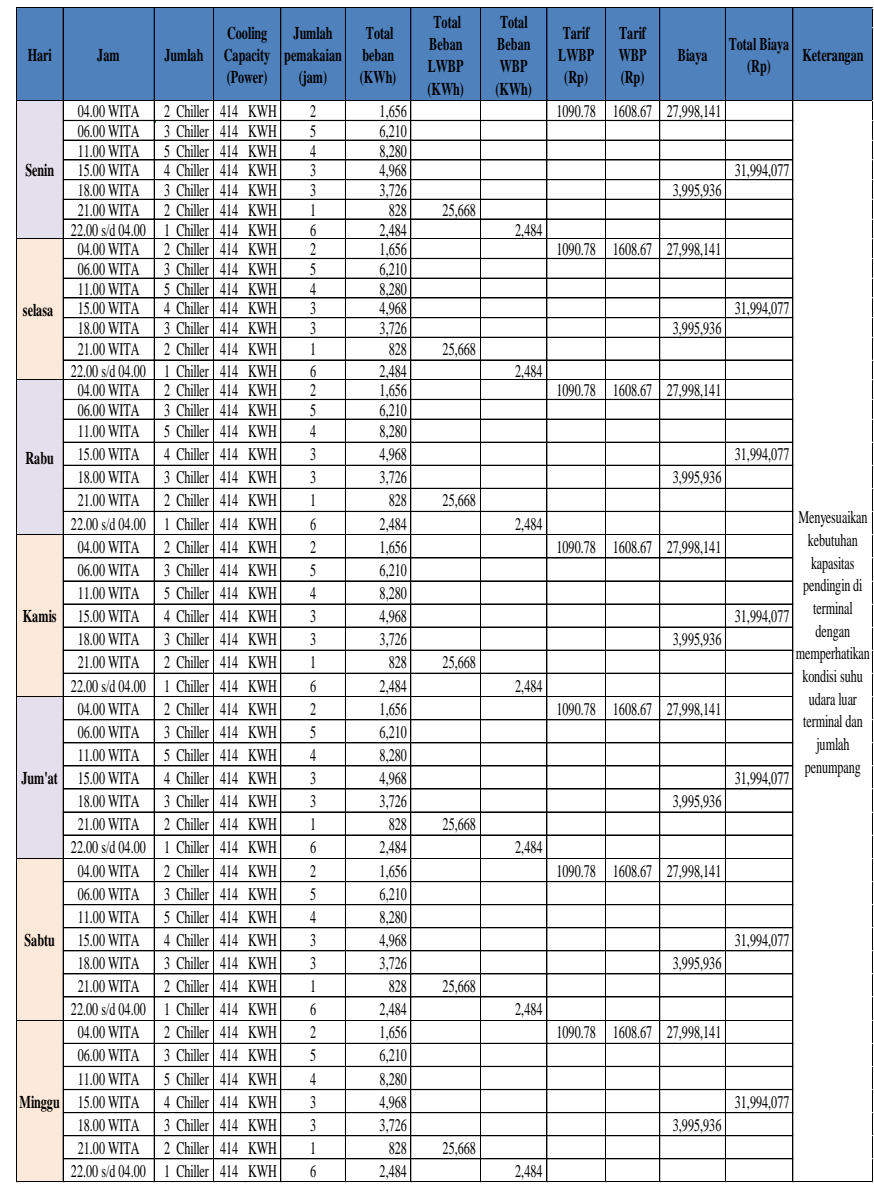

\section{1) Analisa Penggunaan Chiller}

Pada Bandara Syamsudin Noor untuk memenuhi kebutuhan udara dingin menggunakan Chiller yang memiliki kemampuan mengolah dan mensuplai air dingin.Untuk dialirkan ke AHU dan FCU, Chiller sebagai mesin pendingin utama. Chiller yang digunakan adalah 5 unit, sedangkan jumlah total unit Chiller yang terpasang sebanyak 6 unit di mana masing-masing unit mempunyai kapasitas sebesar 409 TR (Ton Refrigerant). Dimana Chiller beroperasi sesuai kapasitas kalori masing-masing, sehingga untuk melakukan pengontrolan Chiller harus mengetahui kapasitas kalori terlebih dahulu. Adapun perhitungan kalori Chiller adalah sebagai berikut:

Untuk 6 unit Chiller yang digunakan mempunyai kapasitas yang sama yaitu 409 
TR. Dimana 1 TR $=3.024$ Kalori. Maka 409 TR x $3.024=1236,816$ Kalori.

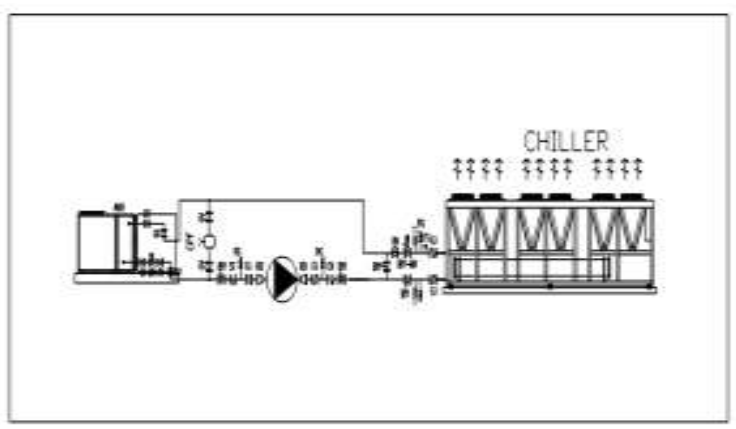

Gambar 1. Wiring instalasi Chiller

\section{2) Pengoperasian Chiller Dengan Cara manual}

Dari hasil data pengoperasian Chiller di Bandara Syamsudin Noor pelaksanaan pengaturan waktu jam operasional Chiller dalam 24 jam masih dioperasikan dengan cara manual, dengan jumlah Chiller sebanyak 6 unit yang memerlukan konsumsi listrik sebesar 414 Kwh dalam satu unit Chiller. Namun dalam pengopesian Chiller terdapat waktu atau jadwal yang telah ditentukan untuk menghidupkan dan mematikan Chiller dengan menyesuaikan kebutuhan kapasitas pendingin di terminal Bandara Syamsudin Noor dengan memperhatikan suhu udara luar dan jumlah penumpang.

\section{3) Pengoperasian Chiller Menggunakan BAS}

Dari hasil observasi lapangan dengan cara pengamatan langsung pada mesin pendingin jenis Chiller yang terdapat di Bandara Syamsudin Noor. Pada perencanaan pengoperasian Chiller menggunakan Building Automation System. Akan menambahkan instalasi pada panel kontrol Chiller yang akan dihubungkan dengan Building Automation System yang mana didalam panel tersebut sudah tersedia terminal yang dapat di aplikasi dengan Building Automation System. Sehingga Chiller dapat dioperasikan secara otomatis. terdapat beberapa cara untuk mengoperasikan dan monitor Chiller

\section{Penerapan Penggunaan Building Automation System pada Chiller}

Pada perapan pengunaan Building Automation System digunakan untuk pengopersian Chiller. terdapat beberapa gambar perecaan instalasi Building Automation System yang diaplikasikan pada Chiller, adapun perencanaan instalasi Building Automation System untuk mengoperasikan Chiller sebagai berikut :

\section{Perencanaan Instalasi Building Automation System \\ Building Automation System yang} diaplikasi untuk pengoperasiakan dan monitor Chiller, yang di hubungkan dengan Building Automation System. pada jaringan instalasi BAS untuk mengoperasikan Chiller menggunakan kabel UTP dan konektor RJ 45 yang digunakan untuk menghubungkan antara panel DDC dan panel Chiller serta peralatan yang dikontrol mengunakan BAS, bertujuan memudahkan dalam pegoperasian dan monitor Chiller dari jarak jauh dan secara otomatis. adapun peralatan Chiller yang hubungkan dengan Building Automation System adalah sebagai berikut:

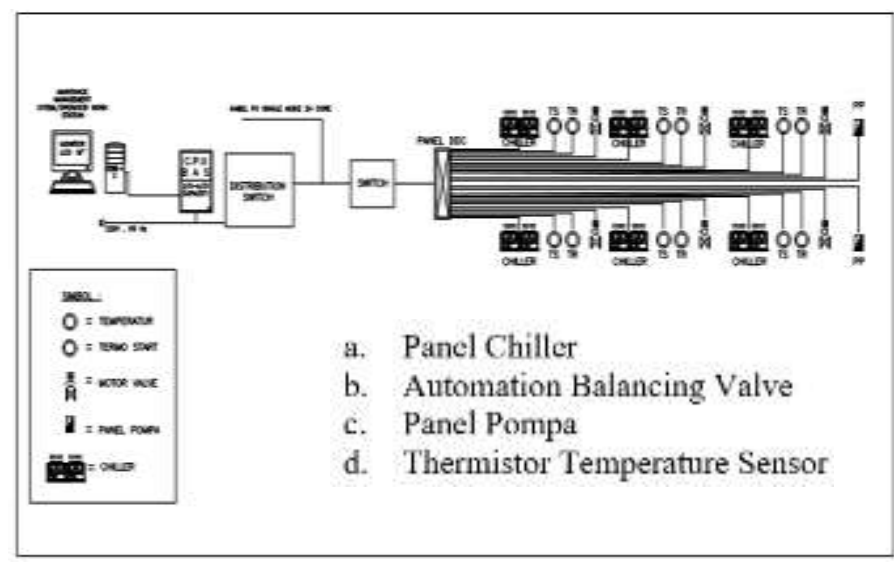

Gambar 2. Wiring Diagram BAS untuk mengoperasikan Chiller

\section{Perencanaan Instalasi Panel Direct Digital Control \\ Dalam perencanaan instalasi panel} DDC terdapat beberapa komponen yang dapat mendukung sistem Direct Digital Control, 
salah satunya adalah modul kontrol yang terdapat didalam panel tersebut . yang berfungsi mengatur komunikasi dari server BAS untuk mengoperasikan dan monitor Chiller dari jarak jauh dan secara otomatis. Dengan cara kerja sistem mengendalikan star / stop peralatan yang dikontrol sesuai perintah ataupun jadwal yang telah ditentukan maka cad digital output (DO) DDC akan mengeluarkan tegangan $24 \mathrm{vcd}$ untuk mengaktifkan relay panel BAS saklar relay yang awalnya NO (Normally Open) akan menjadi NC (Normally Close) sehingga akan mengirim arus pada peralatan yang di kontrol. Pada penerapan Building Automation System untuk mengoperasikan Chiller terdapat dua panel DDC yaitu panel DDC untuk Chiller dan Pompa Chiller.

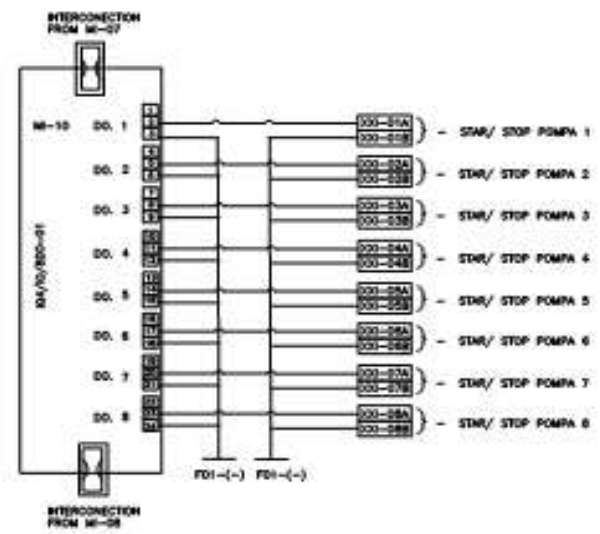

Gambar 3. Wiring Diagram panel DDC Pompa Chiller

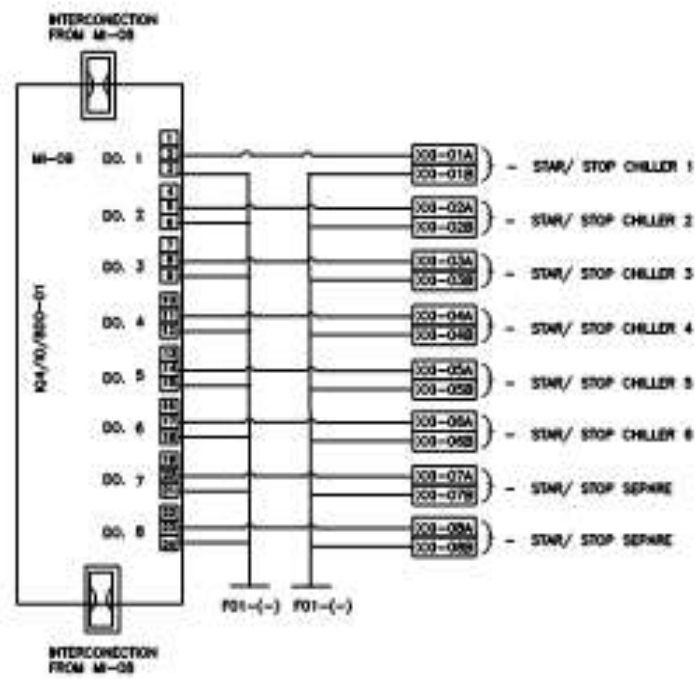

Gambar 4. Wiring Diagram panel DDC Chiller

\section{Perencanaan instalasi Terminal Block}

Pada panel Building Automation System terdapat terminal block yang berfungsi sebagai panel penghubung antara kabel instalasi dari modul panel DDC dan instalasi Chiller serta peralatan pendukung sistem instalasi Chiller yang dioperasikan maupun dimonitor oleh BAS. Terminal block juga berfungsi untuk instalasi power supply module pada panel DDC. Dengan bertujuan adanya terminal block akan memudahkan untuk melakukan pengecekan apabila terjadi masalah pada sistem instalasi peralatan Chiller yang diaplikasikan menggunakan Building Automation System

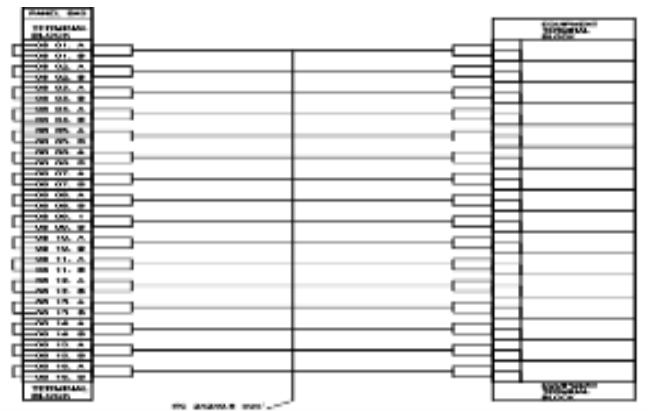

Gambar 5. Panel Terminal Block BAS

\section{Sistem Kelistrikan Chiller}

Konsumsi energi listrik pada Chiller di Bandara Syamsudin Noor cukup besar, sehingga dibuat sistem kelistrikan khusus untuk energi listrik pada panel Chiller dan peralatan pendukung lainya. Adapun wiring sistem kelistrikan pada Chiller.

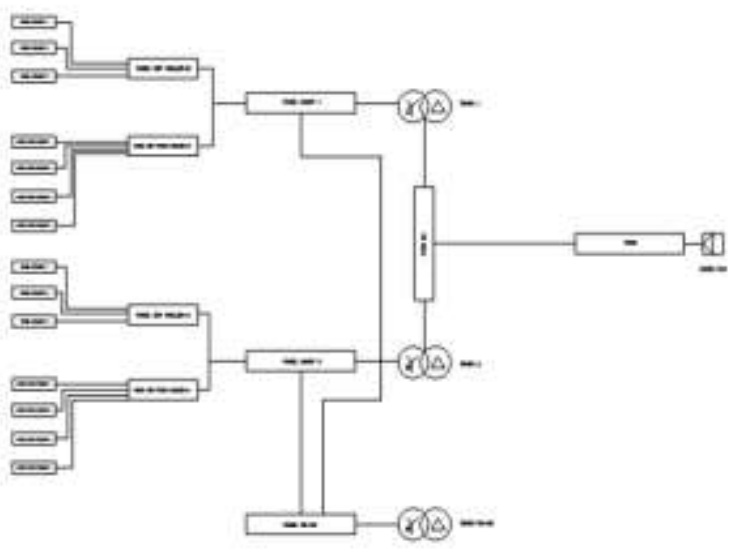

Gambar 6. Wiring Diagram Distribusi Panel Listrik Chiller 
Pada gambar wiring diagram distribusi listrik untuk menghidupkan Chiller dan peralatan pendukung lainya menggunakan jaringan tegangan menengah, yang mana mendapatkan suply langsung dari gardu utama Bandara Syamsudin Noor yang dihubungkan ke panel cubicle dan ketiga unit trafo dengan sistem looping yang akan didistribusikan ke sup distribusi panel (SDP) yang akan dibagikan ke masing-masing panel utama peralatan Chiller dan panel peralatan lainya. Dengan sistem tersebut energi listrik pada Chiller tidak akan terganggu apabila ada masalah pada distribusi listrik lainya. Sehingga energi listrik untuk menghidupkan Chiller lebih handal dan aman.

\section{1) Dampak Pengoperasian Menggunakan Building Automation System}

Perencanaan penggunaan Building Automation System untuk pengoperasian Chiller, bertujuan untuk mempermudah pengoperasian dan monitoring yang sebelum menggunakan BAS pengoperasian Chiller masih secara manual dengan cara operator harus datang ke lokasi untuk menghidupkan sesuai jadwal operasional yang ditentukan. Dengan menggunakan Building Automation System dapat menghemat biaya energi listrik dan biaya operasional. Pada saat pengoperasian Chiller masih manual daya listrik yang digunakan 30,636 Kwh per hari setelah menggunakan Building Automation System untuk mengoperasikan Chiller daya listrik yang digunakan 28,152 Kwh per hari sehingga terdapat penghematan energi listrik sebesar 30,636 Kwh - 28,152 Kwh = 2,484 Kwh per hari. Jika dikonversikan ke rupiah, terdapat penurunan biaya listrik sebesar Rp 2,713,632. Berdasarkan tarif listrik PLN yang digunakan Bandara Syamsudin Noor, dengan tarif luar waktu beban puncak (LWBP) Rp 1090.78 per Kwh dan waktu beban puncak (WBP) Rp 1608.67 per Kwh

Sehingga terdapat jam tertentu yang menggunakan masing-masing tarif operasional Chiller dari jam 04.00 - 21.00 menggunakan tarif LWBP sedangkan $22.00 \quad-04.00$ menggunakan tarif WBP. Melihat penurunan Konsumsi energi listrik dan biaya listrik yang digunakan untuk pengoperasian Chiller menggunakan Building Atomation System sangat menguntungkan bagi perusahaan dan lebih efesien dalam pekerjaan pengoperasian Chiller

Untuk Pengujian hasil penelitian kita harus mengambil data perbandingan antara monitoring melalui software dan monitoring pengukuran manual, dimana setiap data kita bandingkan antara software dan pengambilan data manual lalu kita buat ke dalam tabel dan kita bandingkan selisih nya berapa persen. Pengujian hasil penelitian dapat kita buat dalam tabel sebagai berikut Pada pengujian ini dilakukan dengan pemasangan beban sebagai berikut :

Tabel 3. Beban yang digunakan

\begin{tabular}{|c|c|c|c|}
\hline No & Beban & $\begin{array}{c}\text { Tegangan } \\
(\mathrm{V})\end{array}$ & $\begin{array}{c}\text { Daya } \\
(\mathrm{W})\end{array}$ \\
\hline 1 & Lampu & $220 \mathrm{~V}$ & $7 \mathrm{~W}$ \\
\hline 2 & Kipas Angin & $220 \mathrm{~V}$ & $20 \mathrm{~W}$ \\
\hline
\end{tabular}

Adapun untuk hasil pengukuran pengujian tegangan ditunjukkan tabel 4 dan pengukuran arus ditunjukkan tabel 5

Tabel 4. Pengukuran Tegangan

\begin{tabular}{|c|c|c|c|c|}
\hline NO & $\begin{array}{c}\text { Jenis } \\
\text { Pengukuran }\end{array}$ & $\begin{array}{c}\text { Tegangan } \\
\text { SolarCell } \\
\text { (VDC) }\end{array}$ & $\begin{array}{c}\text { Tegangan } \\
\text { Battery } \\
\text { (VDC) }\end{array}$ & $\begin{array}{c}\text { Tegangan } \\
\text { Beban } \\
\text { (VAC) }\end{array}$ \\
\hline 1 & $\begin{array}{c}\text { Pengukuran } \\
\text { menggunakan } \\
\text { software }\end{array}$ & $12 \mathrm{~V}$ & $12,79 \mathrm{~V}$ & $220.9 \mathrm{~V}$ \\
\hline 2 & $\begin{array}{c}\text { Pengukuran } \\
\text { menggunakan } \\
\text { alat ukur }\end{array}$ & $12,45 \mathrm{~V}$ & $12,41 \mathrm{~V}$ & $217.8 \mathrm{~V}$ \\
\hline & Selisih & $\mathbf{0 , 4 5 ~ V}$ & $\mathbf{0 , 3 8} \mathbf{~ V}$ & $\mathbf{3 . 1} \mathbf{~ V}$ \\
\hline
\end{tabular}

Tabel 5. Pengukuran Arus

\begin{tabular}{|c|c|c|c|c|}
\hline NO & $\begin{array}{c}\text { Jenis } \\
\text { Pengukuran }\end{array}$ & $\begin{array}{c}\text { Arus } \\
\text { SolarCell } \\
\text { (A DC) }\end{array}$ & $\begin{array}{c}\text { Arus } \\
\text { Battery } \\
\text { (A DC) }\end{array}$ & $\begin{array}{c}\text { Arus } \\
\text { Beban } \\
\text { (A AC) }\end{array}$ \\
\hline 1 & $\begin{array}{c}\text { Pengukuran } \\
\text { menggunakan } \\
\text { software }\end{array}$ & $0,4 \mathrm{~A}$ & $2,14 \mathrm{~A}$ & $0.14 \mathrm{~A}$ \\
\hline 2 & $\begin{array}{c}\text { Pengukuran } \\
\text { menggunakan } \\
\text { alat ukur }\end{array}$ & $0,2 \mathrm{~A}$ & $2,1 \mathrm{~A}$ & $0.1 \mathrm{~A}$ \\
\hline & Selisih & $\mathbf{0 , 2} \mathrm{A}$ & $\mathbf{0 , 4} \mathrm{A}$ & $\mathbf{0 . 4} \mathbf{A}$ \\
\hline
\end{tabular}




\section{KESIMPULAN}

Setelah dilakukan penerapan Building Automation System untuk pengoperasian Chiller terdapat penghematan energi listrik sebesar 2,484 Kwh dan biaya operasioanl listrik sebesar Rp 2.713.632 per Kwh

\section{DAFTAR PUSTAKA}

A.Geetha \& K. Jamuna. Smart Metering System,(2013) information Communication and Embedded

Chevy, Adrian. (2019). RCA Kegagalan Tube Chiller X01 Plant ASP-4. Makalah dalam laporan akar masalah di PT. Pupuk Sriwidjaja Palembang.

Dwitya,Nugraha,Syechu.(2011). Rancang Bangun Building Automation System dengan menerapkan Kontrol Logika Fuzzy.

Halimah (2015). Rancang bangun kendali sistem otomatis bangunan SUB-UNIT Air Handling Unit (AHU)

Mandarani, Putri, dan Zaini,( 2016 ). Pengembangan Sistem Monitoring pada Building Automation System (BAS) Berbasis Web

Mamo, Soudjah (2018) Pengertian Chiller http://www.academia.edu/21551909/Pe ngertian Chiller

Pedro Domingues, Paulo Carreira, Renato Vieira, Wolfgang Kastner (2016) Building Automation System : Concepts and Technology Review, Computer Standards \& Interface 45, 112, Elsevier.

Wahyono, Teguh. (2017). Building \& Maintenance Pc Server.

Wiratno.(2014). Rancang Bangun Sistem AC Otomatis Berbasis Mikrokontroler Atmega 8535 Pada Smart Building 